\title{
Métodos para Avaliação Ergonômica de Joias
}

\author{
Methods for Ergonomic Evaluation of Jewelry
}

\author{
SILVA, Stephany de Souza; B.ela; Universidade Estadual de Santa Catarina \\ pi.stephany@gmail.com
}

SANTOS, Flávio Anthero Nunes Vianna dos; Dr.; Universidade Estadual de Santa Catarina

flavioanvs@hotmail.com

\section{Resumo}

A prática de adornar o corpo como forma de expressar-se é um hábito que se mantém presente desde as culturas mais antigas apesar dos possíveis prejuízos causados por esses adornos. Por tratar de um setor cujo produto tem tanta valia para sociedade e que pode oferecer danos por seu uso, a aplicação de métodos para avaliação ergonômica que indique a qualidade dos produtos disponíveis no mercado pode garantir ao usuário a oferta de joias adequadas que não propiciem prejuízos. Sendo assim foi identificada a necessidade de pesquisar a literatura científica que aborda a temática, verificando como os demais pesquisadores têm realizado suas avaliações, quais os métodos utilizados e como se estruturam. Com a constatação da falta de métodos desenvolvidos com esse propósito, buscou-se compreender como foram guiadas as adaptações de métodos de avaliação tradicionais para essa função.

Palavras Chave: revisão bibliográfica; métodos de avalição; joias.

\begin{abstract}
The practice of decorating the body as a way of expressing itself is a habit that remains present from the oldest cultures despite the possible damages caused by these adornments. Because it deals with a sector whose product is so valuable to society and can offer damages for its users, the application of methods for ergonomic evaluation that indicates the quality of the products available in the market can guarantee to the user the supply of suitable jewels that do not propitiate losses. Therefore, it was identified the need to research the scientific literature that approaches the subject, verifying how other researchers have carried out their evaluations, what methods are used and how they are structured. With the lack of methods developed for this purpose, we sought to understand how the adaptations of traditional evaluation methods for this function were guided.
\end{abstract}

Keywords: bibliografic review; methods of evaluation; jewels. 


\section{Introdução}

O uso de adornos pelo ser humano segundo Gola (2008) não possui datações exatas, mas está presente nos mais antigos registros de sociedades pré-históricas, pelo feitio de ornamentos com função de distinguir, bem como estabelecer semelhança com os demais membros de um grupo. A autora ressalta descobertas arqueológicas de adornos feitos com fibras vegetais e partes de animais, como couro e ossos, minérios também já eram empregados na confecção desses produtos. De acordo com Untracht (2001), por possuir motivação em questões intrínsecas à natureza humana, o ato de adornar-se pode ser visto como um hábito que se manterá presente ao longo da existência da espécie. Atualmente, tal prática persiste mesmo após traumas causados pelo próprio uso de acessórios, como visto por Lane e O’Toole (2001), que apontam a escolha de pacientes que depois de realizarem o procedimento de reconstrução de lóbulo voltam a perfurar suas orelhas para que poudessem continuar a usar brincos.

Desconfortos como vermelhidão e coceiras causados pelo uso de brincos são comuns em $34 \%$ dos usuários segundo Biggar e Haughie (1975). E assim como constrangimentos de maior gravidade, que exigem procedimentos cirúrgicos para sua correção, como queloides e divisão de lóbulo, as causas para essas perturbações podem ter origem desde a perfuração, segundo Lane e O'Toole (2001), realizada de forma irregular com o uso de pistolas, assim como podem ter sua causa no material com o qual o brinco é confeccionado, como salientado por Batista (2015), causando alergias, principalmente no caso de ligas metálicas com níquel em sua composição. A autora também aponta outro fator causador de constrangimentos, o peso dos brincos, a tensão originada pelo peso excessivo pode gerar tração no lóbulo, possivelmente levando à fendas, partindo o local. Stroebel (2014) expõe sobre a necessidade de limites quantitativos para o correto desenvolvimento de projetos na área da joalheria, para evitar que tais prejuízos sejam impostos ao usuário final, levando a danos com possíveis riscos à integridade física do mesmo. A autora aponta para falta de normatização para prática projetual que estejam além das questões acerca da liga metálica empregada na joia.

Diante dos possíveis riscos durante o uso e da falta de indicações para a produção de joias, métodos para verificar os parâmetros ergonômicos do produto se mostram necessários. Investigar esses métodos, consiste em averiguar quais os aspectos da interação do usuário e do produto estão sendo avaliados, como a pesquisa é estruturada e de que forma os dados colhidos são tratados e como seus resultados podem ser aplicados.

\section{Método}

Adornos constituem um vasto grupo de produtos, com joias elaboradas para ornamentar diferentes partes do corpo, com contato superficial com a pele ou até mesmo subcutâneo. Essa pluralidade possibilita eventuais danos à diferentes partes do corpo do usuário, como orelhas, língua ou pescoço, e com prejuízos de classes distintas, como alergias e fissuras. Portanto, a pesquisa deve contemplar métodos de diferentes naturezas, que investigue os diversos aspectos desse nicho de produto.

A avaliação dos métodos aplicados em estudos com foco em análises Ergonômicas de joias foi realizada por meio de uma Revisão Bibliográfica Sistemática (RBS). Para Galvão, Sawada e Trevisan (2004) o processo da RBS demanda seis etapas, sendo a primeira delas a Construção do protocolo; seguida pela Definição da pergunta; sendo a terceira etapa a Busca dos estudos; seguida pela Seleção dos estudos; a qual precede a Avaliação dos estudos; posteriormente é executada a 
Coleta de dados; finalizando o processo com a Síntese de dados. Esses estágios guiam o estudo aqui apresentado.

\section{Revisão Bibliográfica Sistemática.}

\subsection{Construção do protocolo}

A etapa de construção do protocolo estabeleceu os parâmetros para pesquisa, partindo da formulação da pergunta de pesquisa. Para guiar o estudo, critérios para seleção do material bibliográfico foram estabelecidas, sendo elas:

- Conteúdos disponíveis nas línguas de domínio: português, inglês e espanhol;

- Material desenvolvido entre 2000 e 2017.

Os recursos necessários para pesquisa foram obtidos pelo acesso à bancos de dados de periódicos internacionais disponibilizados pela Universidade Estadual de Santa Catarina. A avaliação inicial para seleção foi feita pela leitura dos títulos e resumos dos materiais apresentados na busca.

\subsection{Definição da pergunta de pesquisa}

De forma a direcionar os aspectos a serem explorados no estudo é formulada a pergunta de pesquisa, sendo essa: "Quais métodos de análise ergonômica são aplicados para verificação de usabilidade de joias?". Essa pergunta permite a identificação de métodos desenvolvidos especialmente para avaliação de joias, bem como verificações realizadas com métodos adaptados para essa finalidade.

\subsection{Busca de estudos}

A partir da pergunta de pesquisa, na terceira fase da RBS, a qual consiste na busca de estudos que embasam o conteúdo abordado em bancos de dados, são formuladas strings para encontrar o material compartilhado. Foram estabelecidas palavras-chave usadas na revisão: "métodos", "usabilidade", "joias", "avaliação", "lóbulo" e "normas". A busca por normas de fabricação procurou encontrar possíveis indicações para verificação do comprimento das orientações por elas estabelecidas.

Também foi realizada busca manual de materiais, examinando as referências bibliográficas dos artigos selecionados, e também pelo contato com autores que atuação na área, cujas indicações permitiram o complemento do material encontrado nos bancos de dados.

\subsection{Seleção dos estudos}

Os resultados gerados pelas strings de busca são selecionados através dos critérios de adequação previamente estabelecidos (data de publicação e idioma), os que atenderam ao sistema passam por outra seleção, que consiste na leitura do título do material. Os resultados da busca e seleção estão presentes nos quadros 1, 2 e 3. 
Quadro 1 - String "jewelry" AND "standard"

\begin{tabular}{lcc}
\hline Canal de busca & Artigos encontrados & Artigos selecionados \\
\hline ASTM & 165 & 2 \\
Normas ISSO & 16 & 0 \\
Scielo & 40 & 0 \\
\hline
\end{tabular}

Fonte: Desenvolvido pelos autores

Quadro 2 - String "joalheria"

\begin{tabular}{lcc}
\hline Canal de busca & Artigos encontrados & Artigos selecionados \\
\hline Capes & 41 & 4 \\
\hline
\end{tabular}

Fonte: Desenvolvido pelos autores

Quadro 3 - String "jewelry" AND/OR "evaluation" AND/OR "method" AND/OR "ergonomics"

\begin{tabular}{lcc}
\hline Canal de busca & Artigos encontrados & Artigos selecionados \\
\hline Taylor Francis & 132 & 2 \\
Capes & 405 & 5 \\
Scholar Google & 633 & 3 \\
ScienceDirect & 208 & 0 \\
ProQuest & 80 & 1 \\
\hline
\end{tabular}

Fonte: Desenvolvido pelos autores

Demais strings foram aplicadas, porém seus resultados foram insatisfatórios, apontando estudos com temáticas diferentes da buscada nessa pesquisa. Novamente, o material que se mostrou adequado segue o processo e dá início a uma nova seleção, que nesse caso abarca a leitura completa do estudo.

\subsection{Avaliação dos estudos}

As pesquisas encontradas contribuem para diminuição da lacuna existente nos estudos da prática projetual de Design de joias e sua relação com os Fatores Humanos. Porém essa área da ciência permanece deficiente, o que reforça a justificativa para novos estudos nesse campo, mas dificulta o avanço das pesquisas devido a necessidade de construção de parâmetros que alicerçam tais pesquisas. A avaliação dos estudos foi realizada conforme os seguintes critérios: 
- Aprofundamento nas diretrizes de condução da pesquisa;

- Interpretação dos dados coletados

Dentre os 17 estudos selecionados, apenas 10 proporcionaram contribuição efetivamente para pesquisa.

\subsection{Coleta de dados}

Após a leitura completa dos estudos, pode-se apontar o uso de métodos para verificação de usabilidade de joias ainda não é uma prática comum entre os projetistas.

Testes com intuito de averiguar danos à saúde do usuário que tenham sido causados pela liga metálica aplicada à joia fazem uso de métodos quantitativos, como coleta e análise de material biológico, sangue ou saliva do usuário, levando a dados concretos, verificando a possível liberação de metais durante contato com o produto, ou a fabricação do mesmo. Bociaga e Mitura (2008) investigam a extensão que possíveis efeitos biomédicos no tecido em contato com metal usado em adornos realizando teste em roedores e implantes metálicos subcutâneos.

Nas escassas avaliações dos aspectos ergonômicos e de usabilidade realizada nos estudos encontrados, cujo enfoque não esteja no material da joia, as mesmas se respaldam na percepção subjetiva da interação do usuário com o produto, tendo como base questionários e a observação do pesquisador sobre o manuseio da joia pelo usuário. Nascimento et al (2016) sugere um procedimento distinto para verificação do comportamento do peso do brinco durante o uso, confrontando as informações com o peso do produto em estado de inércia, o qual será descrito junto dos demais métodos aplicados na síntese de resultados.

\section{Métodos Identificados}

Os meios de análise aplicados para avaliação ergonômica de joias identificados pela RBS apontam a falta de métodos desenvolvidos especificamente para o estudo desse aspecto nos produtos do setor joalheiro. Diferentes métodos e ferramentas rotineiramente aplicados na Ergonomia Física têm sua estrutura reformulada para ajustar-se às necessidades do pesquisador e seus objetos de estudo. Os métodos identificados no material selecionado pela RBS podem ser descritos da seguinte forma:

\subsection{Questionário}

Chagas (2000) afirma que não há padrão para formulação de um questionário, mas algumas recomendações sobre a estrutura devem ser consideradas no momento de construção do método, o qual puramente trata de um conjunto de questões acerca do tema de pesquisa.

Segundo Chagas (2000), o procedimento ocorre da seguinte forma:

- Definir quais informações serão buscadas, relacionando-as com o problema de pesquisa, hipótese e demais métodos de análise aplicados no estudo;

- Determinar o formato das perguntas (abertas, múltipla escolha, dicotômicas) e como serão respondidas, assim como seu texto, ordem e lay-out do formulário;

- Realização de pré-teste, para verificar a efetividade do questionário. Se forem apontados muitos erros no método, o mesmo deverá passar por novos pré-testes após as alterações até que se mostre apto para aplicação. 
Vantagens: Com a devida estruturação a densidade da informação colhida pode ser de grande valor para pesquisa.

Desvantagens: Noelle-neumann (1970) aponta a responsabilidade do pesquisador durante a elaboração do texto do questionário, pois sua má construção pode alterar as respostas dadas pelo sujeito, levando a resultados inconsistentes.

Adequações para o Design de joias: A estrutura do método é direcionada para questões relativas à interação com a(s) joia(s) e aprofundando tópicos sobre aspectos do modelo investigado.

\subsection{Observação}

Staton et al. (2005) estrutura o método em 4 etapas:

- Delimitação da(s) tarefa(s) em estudo;

- Especificação da amostra, o autor reforça a importância na escolha da amostra utilizada na avaliação, para que essa seja representativa da população a qual o produto foi desenvolvido;

- Apontar no protocolo quais aspectos da tarefa serão analisados (tempo de realização, erros, comportamento ou comentários);

- Indicar o modo de verificação e tratamento dos dados colhidos. Um meio de verificar a confiabilidade do material é pela análise de dois observadores sobre a realização da mesma tarefa;

O autor ainda indica que seja feito um diálogo prévio com os participantes da amostra, para que os mesmos se habituem com o método, diminuindo as chances de alterações comportamentais. O uso de máquinas para registros fotográficos permite menor interferência do observador sobre o sujeito, uma vez que esse não nota que está sendo observado, porém questões éticas inviabilizam essa prática.

Vantagens: As informações colhidas podem apontar padrões no comportamento coletivo, de um grupo em específico ou de forma individualizada, além de possibilitar o estudo da interação do usuário com o produto da forma mais próxima ao real.

Desvantagens: Segundo Staton et al. (2005), durante a observação a presença do observador pode gerar ruídos ao resultado, pela possível mudança de comportamento do observado durante a realização da tarefa avaliada. Ter conhecimento da presença de um observador pode ser o suficiente para que sujeito observado altere seu modo de interação com o produto, agindo conforme acredita que o profissional espera dele, mesmo que a ação divirja de suas ações naturais. Além disso, esse método pode demandar recursos e tempo.

Adequações para o Design de joias: Nesse caso o método manteve sua organização direcionada pelo estudo do comportamento dos usuários, apenas direcionou seu foco para interação do usuário com a(s) joia(s).

\subsection{Testes subcutâneos}

Com o intuito de verificar os possíveis efeitos da liga metálica empregada em joias que tenham contato com tecidos vivos e fluídos corporais, principalmente pelo aumento de adeptos ao uso de piercings subcutâneos, Bociaga e Mitura (2008) testaram o comportamento de joias modificadas por RF PACVD - radiofrequência e MW/RF PACVD microondas/radiofrequência sobre a 
saúde de ratos machos com implantes subcutâneos. A submissão do metal a tais condições de radiofrequência permite simular possíveis reações da joia após influências sofridas depois da colocação da mesma pelo usuário.

Procedimentos seguidos pelos autores:

- São definidos os interesses do teste e aspectos a serem avaliados;

- O material, métodos de modificação da liga metálica e amostra são definidos;

- A amostra é dividida em grupos (um para modificação via RF PACVD, outro para MW/RF PACVD, um terceiro para joias sem modificação, além de um grupo com operação simulada e outro para controle);

- Amostras de sangue e tecido para análise são colhidos após 24 horas, 1 semana, 4 semanas e 26 semanas e suas informações são avaliadas.

Vantagens: Fornece dados quantitativos sobre possíveis reações alérgicas, complicações cutâneas e até mesmo alterações metabólicas e do funcionamento de órgãos de diferentes sistemas do corpo que possam ter causa na liga metálica das joias.

Desvantagens: Alta demanda de tempo, recursos financeiros e faz uso de roedores para os testes. Além de exigir treinamento qualificado e uma equipe interdisciplinar.

Adequações para o Design de joias: Nesse caso adequação do método se deu pela escolha da liga metálica do objeto implantado nos animais, aço inoxidável cirúrgico 316L. A opção eleita se guiou pela frequência de seu emprego em piercings utilizados por escolas de formação de profissionais da área. Um dos meios de coleta de dados para análise é pela amostra de sangue. Aktepe et al. (2015) realizou testes simples de análise sanguínea com grupos de alta exposição aos materiais usados na confecção de joias, nesse estudo especificamente com trabalhadores da área, salientando o possível uso desse meio como ferramenta de identificação de liberação de metais danosos à saúde humana no organismo daqueles que tenham contato com a matéria.

\subsection{Estudo de cinemetria}

Segundo Mochizuki e Amadio (2003) o método de medição por cinemetria pode ser resumido como a monitoração de um movimento pela marcação de um ponto do corpo estudado, fazendo uso de fotografias para registro do trajeto desse ponto.

Nascimento et al. (2016) organiza o método em 4 etapas:

- Preparação do objeto por meio da confecção e posicionamento dos pontos reflexivos no mesmo;

- Controle do ambiente: ajuste de iluminação, calibração da esteira (para realizar movimentos de teste), posicionamento e regulação da câmera;

- Colher dados a partir de fotografias tiradas durante a execução dos movimentos de teste;

- Tratar e avaliar dados

Vantagens: Aponta o comportamento do objeto durante o uso; fácil treinamento.

Desvantagens: Exige tempo e equipamentos para realização dos cálculos da análise de dados. 
Adequações para o Design de joias: Assim como em métodos anteriormente citados, o ajustamento do estudo se dá pelo objeto com qual os testes são realizados, porém os demais meios de captura de dados e fórmulas para interpretação dos mesmos se mantém comum aos demais estudos desse segmento da biomecânica.

\subsection{Teste de tensão}

A Sociedade Americana para Testes (ASTM) aponta como um dos procedimentos de verificação de usabilidade de joias infantis testes para avaliar a resistência de tensão das peças. Com esse procedimento pode ser estimado se o produto é seguro quanto ao seu rompimento causado por tração, em casos de possíveis acidentes nos quais a joia seja puxada do usuário, como ao enroscar de um brinco.

Procedimentos segundo a ASTM (2014):

- Primeiramente a joia deve ser fixada a uma haste e então a ela é atrelada uma polia, com orientação vertical ou horizontal;

- É exercida uma força de $15 \mathrm{lb}$ sobre a joia durante 5 segundos e sustentada por 10 segundos. A peça será reprovada em caso de rompimento.

Vantagens: Pode ser aplicado em diferentes segmentos da joia, detectando pontos de fragilidade do projeto.

Desvantagens: Exige equipamento adequado para sua aplicação.

\subsection{Demais métodos identificados}

Outros métodos de avaliação foram identificados, porém os mesmos eram direcionados primordialmente para composição da liga metálica e como a interação da mesma se dava com trabalhadores da indústria joalheira. Os métodos tinham como base a coleta e análise de amostras sanguíneas, como em Kielhorn et al (2002), ou com amostras de saliva, como em Guney, Nguyen e Zagury (2014), avaliando possíveis resíduos de metais e danos ao DNA por eles causados. A ASTM (2014) também indica o uso de verificação da liga metálica por testes com ímãs, quantificando o uso de metais magnéticos. A utilização de cádmio também é verificada para garantir a aplicação dentro do limite estabelecido conforme o estabelecido pela ASTM (2014).

\section{Resultados e Discussão}

Conforme identificada por Silva e Batista (2017), bem como por Nascimento et al. (2016), a escassez de diretrizes para fundamentação de diferentes momentos durante o processo de desenvolvimento de produtos no setor de Design de joias foi reforçada com os resultados obtidos pela RBS apresentada neste estudo. Especificamente ao que concerne os aspectos ergonômicos desse setor, a escassez de instruções pode levar a danos à saúde do usuário. Alguns estudos apontaram avanços no desenvolvimento de métodos para outros momentos da prática projetual, como em Liu (2008) e seus estudos na incorporação de dados antropométricos colhidos por meio de fotografias, todavia a execução desse método como um meio de avaliação não foi relatada pelo autor. Assim como na metodologia proposta por Batista (2017), ressaltando a importância da avaliação ergonômica para o Design de joias.

De modo a verificar o cenário no qual esses produtos possam causar danos durante sua utilização com um contingente escasso de métodos de avaliação ergonômica a adaptação de 
protocolos de avaliação se apresentou como a opção mais adequada para os pesquisadores.

Dentre os 10 estudos selecionados na RBS todos os métodos identificados se tratavam de adaptações. A relação dos métodos abordados se apresentou da seguinte forma, como exemplificado no gráfico 1 :

Gráfico 1 - Relação de métodos por artigos.

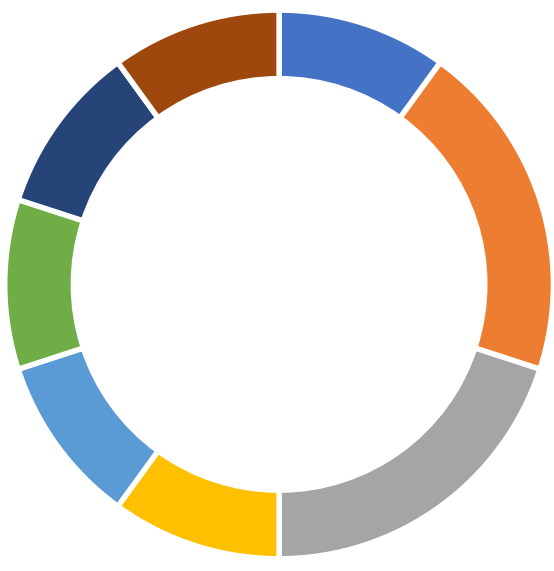

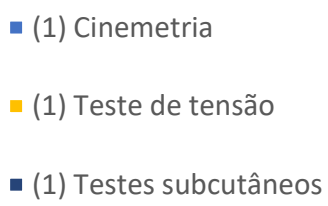

- (1) Cinemetria

- (1) Testes subcutâneos

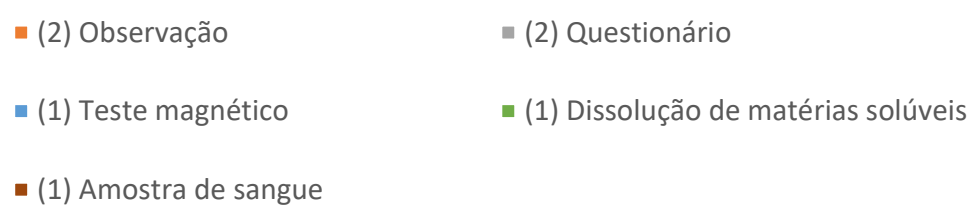

Fonte: Desenvolvido pela autora.

Durante o estudo observou-se que as adaptações para que as ferramentas atendessem aos objetivos das pesquisas consistem em:

- Escolha dos materiais para os produtos de teste: a escolha da liga metálica influencia na possível liberação de metais no organismo, bem como no peso da joia devido sua densidade.

- Peso suportado pela joia, assim como a trajetória da mesma quando utilizada em movimento e possíveis deformações causada aos usuário pelo deslocamento do centro de massa.

- Investigação dos hábitos de uso e da morfologia do usuário para comparar sua percepção de desconforto sobre o produto.

Essas observações reforçam o valor da estruturação de um método de avaliação para joias que abarque as particularidades dos produtos desse setor. Proporcionando a coleta de dados qualitativos e quantitativos, conectando fatores como os citados por Silva (2016), avaliando a usabilidade, conforto e sua adequação aos conceitos semânticos do produto.

Métodos como a Observação e o Questionário não demostraram adaptações de grande relevância, a estrutura foi mantida e apenas as questões aplicadas tinham relação com o objeto de estudo, as joias. Isso aponta a possibilidade de uso de métodos já bem estabelecidos na literatura como um meio de pesquisa sólido. 
Os dados colhidos nos estudos nos quais os métodos investigados foram aplicados contribuem para formação de uma literatura científica melhor estruturada sobre o setor joalheiro. Esses avanços possibilitam formar parâmetros que auxiliem o processo de design desse domínio.

\section{Conclusão}

Os resultados da RBS sobre a inexistência de métodos avaliativos desenvolvidos exclusivamente para análise da interação das joias com o usuário podem ser confirmados por demais estudos na área. A contribuição da pesquisa se dá pela indicação dos pontos os quais devem ser adaptados para formulação de um método de avaliação eficiente para verificação dos aspectos ergonômicos desses produtos. Com esse estudo a importância da estruturação de métodos e ferramentas voltados para o Design de Joias é salientada, apontando o uso de métodos de avaliação sem a necessidade de alterações em sua estrutura, bem como pequenas modificações permitem o emprego demais métodos às pesquisas do setor.

\section{Referências}

AKTEPE, Necmettin et al. Increased DNA Damage and Oxidative Stress Among Silver Jewelry Workers. Biological Trace Element Research, [s.I.], v. 164, n. 2, p.185-191, 10 jan. 2015. Springer Nature. http://dx.doi.org/10.1007/s12011-014-0224-0.

BATISTA, C. R. Human Factors in the earrings design. In: EAD 11, Paris. 11th European Academy of Design Conference, 2015

BATISTA, Claudia Regina. A contribution for Jewelry Design Teaching. The Design Journal, [s.l.], v. 20, n. 1, p.4726-4729, 28 jul. 2017. Informa UK Limited. http://dx.doi.org/10.1080/14606925.2017.1352973.

BIGGAR, R. J.; HAUGHIE, G. E. Medical problems of ear piercing. New York State Journal of Medicine, 75(9), 1460-1462, 1975

BOCIAGA, D.; MITURA, K.. Biomedical effect of tissue contact with metallic material used for body piercing modified by DLC coatings. Diamond And Related Materials, [s.I.], v. 17, n. 7-10, p.14101415, jul. 2008. Elsevier BV. http://dx.doi.org/10.1016/j.diamond.2008.02.014.

CHAGAS, A. T. R.. O questionário na pesquisa científica. Administração On Line (São Paulo), São Paulo, v. 1, n.1, p. 1-14, 2000.

GALVÃO, Cristina Maria; SAWADA, Namie Okino; TREVIZAN, Maria Auxiliadora. Revisão Sistemática: Recurso que Proporciona a Incorporação das Evidências na Prática da Enfermagem. Revista Latinoamericana de Enfermagem, Ribeirão Preto, v. 12, n. 3, p.549-556, maio 2004. Bimestral. Disponível em: <http://www.scielo.br/pdf/rlae/v12n3/v12n3a14.pdf>. Acesso em: 07 nov. 2017.

GOLA, Eliana. A joia: história e design. São Paulo: Senac São Paulo, 2008.

LANE, J. C.E.; O'TOOLE, G. Complications of ear rings. Journal of plastic, reconstructive \& aesthetic surgery by Elsevier Ltd.: JPRAS. V. 65, n. 6, 2011

LIU, Bor-shong. Incorporating anthropometry into design of ear-related product. Applied Ergonomics [S.I.], v.39, n.1, p. 115-121, jan. 2008. Elsevier BV.

MOCHIZUKI, Luis; AMADIO, Alberto C.. Aspectos biomecânicos da postura ereta: a relação entre o centro de massa e o centro de pressão. Revista Portuguesa de Ciências do Desporto, Porto, v. 3, n. 
3, p.77-83, jul. 2003.

NASCIMENTO, Elisa Strobel do et al. RISCOS NO USO DE BRINCOS TIPO PÊNDULO: UM ESTUDO DE CINEMETRIA. Ergodesign \& Hci, Rio de Janeiro, v. 4, n. 1, p.22-30, out. 2016.

NOELLE-NEUMANN, Elisabeth. Wanted: Rules for Wording Structured Questionnaires. Public Opinion Quarterly, [s.I.], v. 34, n. 2, p.191-201, 1970. Oxford University Press (OUP). http://dx.doi.org/10.1086/267789.

SILVA, Stephany de Souza; BATISTA, Claudia Regina. ESTUDO DE CASO: O DESIGN DE JOIAS DE UM FIGURINO DE DANÇA ORIENTAL. In: CONGRESSO INTERNACIONAL DE ERGONOMIA E USABILIDADE DE INTERFACES HUMANO TECNOLÓGICA: PRODUTO, INFORMAÇÕES AMBIENTES CONSTRUÍDOS E TRANSPORT, 16., 2017, Florianópolis. Proceedings. Florianópolis: Blucher, 2017. p. 84 - 96. Disponível em: <http://www.proceedings.blucher.com.br/article-details/estudo-de-caso-o-designde-joias-de-um-figurino-de-dana-oriental-25640>. Acesso em: 19 nov. 2017.

STANTON, Neville et al (Ed.). Handbook of Human Factors and Ergonomics Methods. [s.i]: Crc Press, 2005.

STROEBEL, Elisa. Percepção de desconforto no uso de brincos: relação das características sociodemográficas, morfoantropométricas, dos hábitos relacionados ao uso e da preferência quanto ao tipo de produto. 2014. 294 f. Dissertação (Mestrado) - Curso de Design, Udesc, Florianópolis, 2014. Disponível em: <http://tede.udesc.br/handle/handle/2024>. Acesso em: 9 set. 2017

UNTRACHT, O. Jewelry Concepts and Technology. Great Britain; Robert Hale \& Company, 2001.

\section{Referências Bibliográficas - Artigos científicos selecionados na Revisão Bibliográfica Sistemática}

AKTEPE, Necmettin et al. Increased DNA Damage and Oxidative Stress Among Silver Jewelry Workers. Biological Trace Element Research, [s.I.], v. 164, n. 2, p.185-191, 10 jan. 2015. Springer Nature. http://dx.doi.org/10.1007/s12011-014-0224-0.

AMERICAN SOCIETY FOR TESTING. ASTM F2923-14: Standard Specification for Consumer Product Safety for Children's Jewelry, West Conshohocken, PA, 2014.

AMERICAN SOCIETY FOR TESTING. ASTM F2999-14: Standard Specification for Consumer Product Safety for Adult Jewelry, West Conshohocken, PA, 2014.

BOCIAGA, D.; MITURA, K.. Biomedical effect of tissue contact with metallic material used for body piercing modified by DLC coatings. Diamond And Related Materials, [s.I.], v. 17, n. 7-10, p.14101415, jul. 2008. Elsevier BV. http://dx.doi.org/10.1016/j.diamond.2008.02.014.

GUNEY, Mert; NGUYEN, Aliain, ZAGURY, Gerald J.. Estimating children's exposure to toxic elements in contaminated toys and children's jewelry saliva mobilization. Journoal of Envoironmental Science And Health. [S.I.], v. 49, n 11, p. 1218-1227, 26 jun. 2014. Informa UK Limited

HOCHMAN , Bernardo et al. Does ear keloid formation depend on the type of earrings or piercing jewellery? Australasian Journal Of Dermatology, [s.I.], v. 56, n. 3, p.77-79, 25 fev. 2015. WileyBlackwell. http://dx.doi.org/10.1111/ajd.12190.

KIELHORN, Janet et al. Palladium - A review of exposure and effects to human health. International 
Journal Of Hygiene And Environmental Health, [s.I.], v. 205, n. 6, p.417-432, jan. 2002. Elsevier BV. http://dx.doi.org/10.1078/1438-4639-00180.

NASCIMENTO, Elisa Strobel do et al. RISCOS NO USO DE BRINCOS TIPO PÊNDULO: UM ESTUDO DE CINEMETRIA. Ergodesign \& Hci, Rio de Janeiro, v. 4, n. 1, p.22-30, out. 2016.

THIEN, Laura J. Body piercing: Clinical considerations. American Journal Of Nursing, [S.I.], v. 15, n.1, p.29-35, jan. 2005.

SILVA, Stephany de Souza; BATISTA, Claudia Regina. ESTUDO DE CASO: O DESIGN DE JOIAS DE UM FIGURINO DE DANÇA ORIENTAL. In: CONGRESSO INTERNACIONAL DE ERGONOMIA E USABILIDADE DE INTERFACES HUMANO TECNOLÓGICA: PRODUTO, INFORMAÇÕES AMBIENTES CONSTRUÍDOS E TRANSPORT, 16., 2017, Florianópolis. Proceedings. Florianópolis: Blucher, 2017. p. 84 - 96. Disponível em: <http://www.proceedings.blucher.com.br/article-details/estudo-de-caso-o-designde-joias-de-um-figurino-de-dana-oriental-25640>. Acesso em: 19 nov. 2017. 